\title{
PLANEJAMENTO E MOBILIDADE URBANA NO BRASIL: O USO DA BICICLETA COMO UMA NOVA MANEIRA DE PENSAR E CONSTRUIR A CIDADE
}

Planning And Urban Mobility In Brazil: The Use Of The Bicycle As A New Way To Think And Build The City

\section{Janio Laurentino de Jesus Santos}

Universidade Estadual de Feira de Santana (UEFS), Feira de Santana, BA, Brasil.

Lattes: http://lattes.cnpq.br/2282494423261197. ORCID: https://orcid.org/0000-0003-0730-1271.

E-mail: janiosantos@yahoo.com.br

\section{Luiz Eduardo Pereira Ferreira dos Santos}

Universidade Estadual de Feira de Santana (UEFS), Feira de Santana, BA, Brasil. Lattes: http://lattes.cnpq.br/4367635562880571 ORCID: https://orcid.org/0000-0002-1031-0884.

E-mail: edugeouefs@yahoo.com.br

Trabalho enviado em 17 de julho de 2020 e aceito em 23 de abril de 2021

\section{(c) (i)}

This work is licensed under a Creative Commons Attribution 4.0 International License. 


\section{RESUMO}

A infraestrutura urbana foi construída para beneficiar as necessidades dos veículos automotores e isso é algo que se dá historicamente na formação das cidades em todo o mundo. Espaços que seriam de uso dos pedestres em geral, como espaços públicos e passeios, foram reduzidos, com o objetivo de alargar das vias, e os espaços para ciclistas e skatistas, como as ciclovias, não são prioridades. Nessa direção, este artigo tem como objetivo apontar, assim como problematizar, a questão da mobilidade urbana no Brasil, com ênfase no uso da bicicleta e, atrelado a isto, avaliar o planejamento urbano e ciclístico. O foco é refletir sobre as contradições que se revelam no contexto da produção das cidades, com ênfase no papel do Estado e das gestões municipais, ante as escolhas e interesses que enredam o tema. O texto foi elaborado com base em pesquisa bibliográfica e documental, bem como em investigações sobre algumas cidades brasileiras. Entende-se que a bicicleta precisa ser integrada à totalidade do sistema de mobilidade, e assim, com a maior importância desse modal, conjuntamente com a maior qualidade do sistema de transporte público, a cidade poderá ser mais saudável, sustentável, e sobretudo, democrática.

Palavras-chave: Planejamento Urbano, Mobilidade Urbana, Bicicleta, Uso, Cidades

\section{ABSTRACT}

Urban infrastructure was built to benefit the needs of automobiles and this is something that has historically been built in cities around the world. The spaces that would be used by pedestrians, such as public spaces and sidewalks, have been reduced, with the aim of expanding the roads, and the spaces for cyclists and skaters, such as bicycle paths, are not a priority. This article aims to understand and problematize urban mobility in Brazil, with an emphasis on the use of bicycles and to evaluate urban and cycling planning. The focus is to reflect on the contradictions that are revealed in the context of the production of cities, with an emphasis on the State and municipal administrations, given the choices and interests that involve the theme. The text was prepared based on bibliographic and documentary research, and investigations on some Brazilian cities. The bicycle needs to be integrated into the mobility system. With the increasing importance of this mode, together with the higher quality of the public transport system, the city may be healthier, more sustainable, and above all, more democratic.

Keywords: Urban Planning, Urban Mobility, Bicycle, Use, City. 


\section{INTRODUÇÃO}

Nas últimas décadas, principalmente nos países da periferia do capitalismo, as cidades obtiveram um grande crescimento e transformaram um país como o Brasil, que durante séculos se estruturou com base na economia rural, em urbano. Essa urbanização, segundo Harvey (2005), é um processo social espacialmente fundamentado, em que uma diversidade de atores sociais, de diversas origens sociais, com distintos compromissos e objetivos interagem com base em práticas espaciais entrelaçadas. Como vivemos em uma sociedade organizada face os conflitos de classes antagônicas, essas práticas se formam através de um conteúdo de classe explícito e definido, sem esquecer, é claro, os conflitos raciais, de gênero, de etnia, entre outros.

É nesse contexto de urbanização e desigualdades sociais expostas por causa da disputa entre classes, portanto, que se introduz o estudo sobre a dinâmica da mobilidade nas cidades brasileiras, assim como do planejamento urbano mais geral e do planejamento específico sobre a mobilidade urbana. Segundo Maricato (2011), a mobilidade urbana é mais precária nos bairros onde se encontram os moradores de baixa renda, que estão localizados nas "periferias", os quais mostram que a desigualdade socioespacial se reflete nas condições de deslocamento da população. $O$ alto custo da passagem, a baixa rotatividade do transporte público nas áreas periféricas e a falta de infraestrutura e política para os moldais não motorizados, como a bicicleta, fazem com que essa população tenha negado o direito de ter uma mobilidade de qualidade na cidade.

Outro problema encontrado é que a infraestrutura das cidades foi construída para beneficiar as necessidades dos veículos automotores e isso é algo que se deu historicamente na formação das cidades em todo o mundo. Nesse sentido, espaços que seriam de uso dos pedestres em geral, como espaços públicos e passeios, foram reduzidos, com o objetivo de alargar as vias, e os espaços para ciclistas e skatistas, como as ciclovias, não são prioridades para o Estado.

Nessa direção, este artigo tem como objetivo apontar, assim como problematizar, a questão da mobilidade urbana no Brasil, com ênfase no uso da bicicleta e, atrelado a isto, avaliar o planejamento urbano e ciclístico. O foco é refletir sobre as contradições que se revelam no contexto da produção das cidades, com ênfase sobre o papel do Estado e das gestões municipais, ante as escolhas e interesses que enredam o tema. 
O texto foi elaborado com base em pesquisa bibliográfica e documental, bem como em investigações sobre algumas cidades brasileiras, e está organizado da seguinte forma: parte de uma discussão sobre o Estado e seus amálgamas com o planejamento urbano, para, a posteriori, pensar o uso da bicicleta como modo de resistência e existência, uma luta no conjunto de interesses da política urbana; e, por fim, trazer pressupostos para construção de um novo projeto de cidade, em que a bicicleta seja parte do projeto de mobilidade, mais justo, sustentável e inclusivo.

\section{O ESTADO COMO AGENTE DO PLANEJAMENTO URBANO}

Para fazer a reflexão necessária sobre o planejamento urbano no Brasil e no mundo é importante, inicialmente, entender como funciona e se movimenta um dos seus principais agentes, o Estado, ao longo de toda a sua história. De forma hegemônica, o Estado está a serviço dos interesses dominantes locais e regionais e isso é realizado historicamente com muita perceptibilidade nas cidades brasileiras. O processo de produção do espaço urbano se dá na lógica de atender aos elementos econômicos desses interesses, que, em geral, financiam as campanhas políticas dos partidos que estão no controle do poder público municipal. E assim, as reais necessidades da população, como a de ter uma mobilidade urbana de qualidade, não são prioridade (CACCIA, 2015). Assim, a dificuldade primordial das cidades brasileiras é conter os interesses dominantes locais e regionais, que atuam para que o planejamento das cidades permaneça alheio às necessidades da maioria da população.

Nesse sentido, é importante entender o que é o Estado e a quais interesses esse agente serviu ao longo da sua história. Engels (2012) e Lênin (2012) explicam que o Estado Moderno surgiu na história da humanidade quando a evolução das trocas comerciais resultou na divisão do trabalho, entre agricultores, artesões e comerciantes e esse processo resultou na divisão da sociedade em classes antagônicas (ricos vs. pobres, exploradores vs. explorados), que estão presas em conflitos inconciliáveis. Para manter a ordem da sociedade, em benefício da classe dominante vigente, foi criado um aparelho aparentemente por cima dessas classes em luta, e esse aparelho é o Estado, o qual “[...] aparece onde e na medida em que os antagonismos de classes não podem objetivamente ser conciliados e, reciprocamente, a existência do Estado prova que as contradições de classes são irreconciliáveis". (LÊNIN, 2012, P. 27).

E o Estado não é uma imposição de fora para dentro, é produto dessa sociedade, criado como necessidade para amortecer os conflitos entres as classes antagônicas, que são inconciliáveis, e colocálos dentro da ordem estabelecida. Porém, o Estado foi colocado com uma posição superior a sociedade 
que o criou e ao longo da história afastou-se cada vez mais dela. Engels (2012, p. 213) explica essa formação:

O Estado não é pois, de modo algum, um poder que se impôs à sociedade de fora para dentro, tampouco é "a realidade da ideia moral", nem "a imagem e a realidade da razão", como afirma Hegel. É antes de tudo um produto da sociedade, quando esta chega a um determinado grau de desenvolvimento; é a confissão de que essa sociedade se enredou numa irremediável contradição com ela própria e está dividida por antagonismos irreconciliáveis que não consegue conjurar. Mas para que esses antagonismos, essas classes com interesses econômicos colidentes não se devorem e não consumam a sociedade numa luta estéril, faz-se necessário um poder colocado aparentemente por cima da sociedade, chamado a amortecer o choque e mantê-lo dentro dos limites da "ordem". Esse poder, nascido da sociedade, mas posto acima dela se distanciando cada vez mais, é o Estado.

Outro ponto importante em Engels (2012), também encontrado em Harvey (2005), é que o Estado funcionava para beneficiar a classe economicamente dominante naquele período histórico e a transforma em classe politicamente dominante, com a utilização dos instrumentos da força pública, sobretudo a força de polícia, para reprimir e criar novas formas de explorar a classe dominada. No atual contexto, essa classe dominante é a burguesia, que é detentora dos meios de produção. Já foi os senhores de escravos e também a nobreza. Mas, em ambos os casos, o aparelho estatal foi criado e utilizado pela classe dominante para subjugar e explorar a classe oprimida.

Marx e Engels (2007) explicam que o Estado Moderno e o direito estão ligados completamente a propriedade privada. Ele é comprado pelos proprietários privados, principalmente através do sistema de dívida pública, e torna-se dependente do sistema de crédito desses proprietários. Se configura enquanto um aparelho a serviço dessa classe de proprietários, que é a burguesia. Mochi (2009) também comenta que o Estado Moderno foi articulado pela necessidade da formação de um poder político, que por meio desse pudesse garantir a propriedade privada e a reprodução da produção capitalista. Nesse sentido, funciona em todas as suas instituições para garantir os interesses da burguesia e sustentar a continuidade de sua dominação política e econômica na sociedade, inclusive através do direito, que adquire, portanto, uma forma política.

Porém, na sociedade contemporânea o elemento central na luta de classe está na disputa de posição ideológica, em que os diversos grupos sociais, inclusive as classes oprimidas, fazem esforços para a conquista de suas posições no meio e entre a sociedade civil. E nesse sentido, o Estado também é um elemento de disputa. E mesmo tendo acordo com a posição clássica do marxismo sobre o papel do Estado, é necessário entender que, para o avanço das pautas das classes abastadas, é importante 
também lutar pelas pequenas conquistas nessa sociedade a qual nos encontramos. Então, a luta dentro do Estado também se torna imperativa.

Para Gramsci (1984), o Estado em si é a própria sociedade organizada de maneira imperante. Essa sociedade é tida como um conjunto de instituições complexas, que podem ser tanto públicas quanto privadas, se aliam umas com as outras e historicamente variam suas posições através das lutas e relações de grupos específicos, que se articulam e ganham mais poder para garantir a hegemonia dos seus interesses. Então, os governos, para manterem a sua dominação, não usam somente o seu poder de coerção, mas também o do consenso, e constroem a hegemonia de suas posições no meio da sociedade civil. Eles precisam de legitimidade, pois nenhum poder se sustenta só na sociedade política (Estado estrito), mas, também, na sociedade civil. Então, o Estado sempre será um campo de lutas, um paradoxo entre força e consenso.

Diferentemente da visão marxista clássica, Gramsci (1984) aponta que o Estado não é representante exclusivo da burguesia, é na verdade o fruto dos conflitos de posições construídos no cerne da sociedade civil e política. Porém, historicamente, a burguesia hegemoniza a maior parte dos instrumentos que produzem ideologia e junto com seu aparato coercitivo garante o controle maior sobre o aparelho estatal.

Silva (1999), ao comentar sobre a visão gramsciana sobre o Estado, explana que o autor aponta que esse agente não é apenas um aparelho de violência e repressão, mas, igualmente, um aparelho jurídico-político, e que sua intervenção na sociedade civil varia de acordo com as correlações de força entre as frações de classes vigentes.

Ainda sobre a contribuição de Gramsci, Violin (2006) comenta que o Estado se divide em duas esferas, a sociedade política, que é o Estado em sentido estrito, o Estado coercitivo, e a sociedade civil, também chamado de Estado ético, formando desse modo o Estado ampliado. A sociedade política é a junção de todos os mecanismos de controle que a classe dominante utiliza para manter o monopólio local, mecanismos esses que são burocráticos, formados assim para dificultar o acesso da maioria da população a esses, e coercitivos e repressivos, que se utilizam da violência para manter o controle da sociedade nas mãos da classe dominante. Por meio da sociedade política, as classes desempenham sempre uma ditadura através da dominação mediante coerção. Já a sociedade civil é o conjunto de organizações dispostas no meio da sociedade, que elaboram e difundem ideologias, as quais podem ser partidos políticos, igrejas, escolas, sindicatos, movimentos sociais, os meios de comunicação, etc. Através da sociedade civil essas organizações e suas classes almejam a disputa da hegemonia da sociedade, que é produzida face a busca de aliados para as suas posições e constroem, de tal modo, 
uma direção política e o consenso, e dessa forma, a sociedade civil pertence ao aparelho estatal no seu sentido ampliado.

Na disputa pelo Estado ampliado, o consenso adquire em muitas vezes maior importância do que a coerção. Por isso, as classes dominantes hegemonizam o controle dos meios de comunicação e as igrejas, por exemplo, pois, através delas, constroem um consenso na sociedade civil, consenso esse que é a favor dos seus interesses. $E$ as classes subalternas, da mesma forma, tentam se apropriar de outros meios para conquistar também o consenso e disputar a hegemonia, através de outras mídias alternativas, da mobilização social, etc.

Outra reflexão importante em Gramsci é a sua proposta de futuro para o Estado e a sociedade. Segundo Coutinho (2011), para Gramsci, o Estado-coerção, que é a principal característica do Estado capitalista, deve ser transformado em uma sociedade comunista, em um Estado que reine o consenso. Para isso, a sociedade civil necessitará estar em um nível de desenvolvimento que a torne complexa e bem articulada, em que seus indivíduos possam se governar por si próprio, em uma situação intitulada de "autogoverno", sem que isso entre em conflito com a sociedade política (Estado estrito). Para o autor, segundo Gramsci, esse desenvolvimento levaria a superação da divisão entre governantes e governados, o que, intrinsicamente, levaria a superação da sociedade dividida em classes.

Então, apesar de haver divergências com as posições de Marx em relação ao Estado e a sociedade civil, até porque o tempo histórico entre eles é diferente, Gramsci mantém a tradição marxista da superação das classes em sua obra.

Também defensor da ideia de que sociedade civil e Estado não se separam, Santos (1989), ao tecer críticas ao pensamento de Marx sobre sociedade civil/Estado, analisa que esses dois elementos não se distinguem, pois, segundo o autor, não há distinção entre economia e política, isso reduziria a política e o direito a apenas uma ação estatal. Essa visão deixa de perceber que "as relações econômicas eram também relações marcadamente políticas" (SANTOS, 1980, p. 9).

Poulantzas (1980) aponta que não há uma natureza de classe, mas sim uma utilização de classe do Estado. Ou seja, o Estado não é um aparelho que é "natural" da classe dominante. Porém, com todo o poder político que essa classe goza, tanto na sociedade civil, quanto na sociedade política, consegue ser hegemônica na sua disputa e utiliza-se disso para garantir que seus interesses sejam contínuos. 0 autor ainda comenta que o Estado apresenta a estrutura material própria, que não pode ser reduzida somente a dominação política. Essa estrutura é mais complexa e fruto de relações de poder e lutas de classes e intraclasses. E prossegue seu pensamento ao citar que "o aparelho do Estado, essa coisa 
especial, e por consequência temível, não se esgota no poder de Estado. Mas, a dominação política está ela própria inscrita na materialidade institucional do Estado" (POULANTZAS, 1980, p. 17).

Para uma reflexão sobre o Estado, a luz de proporcionar através desse que as classes populares possam, por meio da luta, ter avanços em seus direitos e sua qualidade de vida, é necessário apontar que a classe dominante hegemoniza o aparelho estatal. Porém, não o monopoliza e cabe as classes populares, por meio da organização e da luta, pleitear também a estrutura do Estado, desde a disputa por políticas públicas que garantam melhor qualidade de vida, até aquelas mais ousadas pelo controle dos rumos do Estado, no sentido de sua própria superação.

Essa reflexão permite ajuizar sobre o planejamento urbano nesse modelo de Estado e de sociedade. Maricato (2002) aponta que as ideias estão fora do lugar e o lugar está fora das ideias, o que quer dizer que o planejamento é pensado para atender os interesses e as necessidades de determinada e pequena parcela da população, que vive em locais específicos nas cidades, faz parte das "elites" e não tem comprometimento com a realidade concreta e com as reais necessidades da maior parte dos moradores, que vivem e se organizam a revelia do planejamento. Assim, o planejamento está fora do lugar, pois o que se trata está fora da realidade concreta, e o lugar está fora das ideias, porque a realidade concreta da maior parte da população está fora dos meandros dos planos e planejamentos; ela cria suas próprias formas de organizações.

Essa forma de pensar o planejamento urbano é uma característica dos países que estão na periferia do capitalismo, principalmente os latinos americanos, que têm sua herança advinda dos últimos cinco séculos de um exacerbado patrimonialismo, em que a relação de favor ou de troca é central nas atividades de poder e, principalmente, a esfera pública é tratada como algo privado ou pessoal. Tudo isso se torna ainda mais complexo com a corrupção, que é cerne do sistema capitalista e com um judiciário e parlamento historicamente a serviço das elites ligados ao patrimonialismo (MARICATO, 2009).

Nesse pensamento da autora sobredita, é importante ressaltar que no Brasil os padrões do urbanismo modernista foram aplicados nas cidades de forma extremamente desigual, com formação de núcleos modernos, com infraestrutura e funções adequadas ao seu desenvolvimento em pequenas parcelas da cidade, em geral, nas regiões centrais, onde residem as elites.

Na sociedade contemporânea, em que a globalização e o neoliberalismo ditam a dinâmica das relações produtivas e sociais na sociedade capitalista, o planejamento urbano também sofre influência direta disso. Surge o planejamento estratégico, que, segundo autores como Silva (2008), Maricato (2009; 2011) e Vainer (2002), cumpre o mesmo papel de outras atividades neoliberais, de privatizar, 
desregular, fragmentar, para criar um espaço positivo para o mercado atuar de forma absoluta. A cidade precisa se instrumentalizar para competir com outras cidades, na disputa por investimento e isso torna-se, como a própria Maricato $(2009$, p. 14) expressou, uma "máquina urbana de produzir renda". Nesse tipo de cidade as necessidades da maior parte da população são deixadas de lado, enquanto os interesses privados das grandes corporações são tidos como prioridade.

A constituição de 1988, no Brasil, em função da mobilização de diversos movimentos sociais urbanos, garantiu alguns ganhos com a promulgação dos artigos $182^{\circ}$ e 183으, no sentido de pensar o planejamento urbano na direção de se fazer a reforma urbana. Isso se deu principalmente pela obrigatoriedade de os municípios com mais de 20 mil habitantes desenvolverem o plano diretor e, segundo Faccio (2006), abriu a possibilidade de utiliza-lo como ferramenta da reforma urbana. Porém, segundo a própria autora, na prática, os planos diretores não têm cumprido essa função. Pelo contrário, expressam práticas tecnicistas, que servem como instrumentos de poder e obtenção de privilégios.

Com a aprovação do Estatuto das Cidades, em 2001, pela Lei 10.257/2001, que regulamenta os artigos 182ㅇ e 183 da Constituição Federal de 1988, abriu-se a possibilidade de haver transformações sobre essas práticas, pois uma das ferramentas mais importantes contidas no Estatuto é a forma de gestão do plano diretor, com base na criação de processos mais democráticos, o qual, obrigatoriamente, para ser efetuado, necessita da participação popular. Segundo Faccio (2006, p.5), “[...] a participação popular nos processos de planejamento e gestão dos municípios, constitui-se em um dos elementos mais importantes, para a construção democrática das cidades brasileiras".

Além do processo participativo, o Estatuto das Cidades garantiu, pelo menos no papel, outros ganhos para a reforma urbana. Para Silva (2001), ele tem um papel essencial na restruturação das cidades brasileiras, pois institui e disciplina demandas históricas dos movimentos sociais, da sociedade civil e de associações, como Imposto Predial e Territorial Urbano (IPTU) progressivo, desapropriação com pagamentos em títulos e usucapião. Porém, quase 20 anos após a promulgação do Estatuto esses ganhos ainda não se tornaram realidade concreta nas cidades brasileiras.

Tais processos só acontecem na prática com a pressão popular e com a garantia da participação nos ambientes de decisão. Entretanto, segundo Faccio (2006), o processo participativo é o mais difícil de se concretizar, pois não acontece por decreto ou por lei, e sim através da mobilização dos movimentos sociais urbanos, da sociedade civil, das associações, dentre outros, ao pressionar o poder público para garantir essa democratização. Isso se explica porque as "elites" e hegemonicamente o poder público veem o planejamento urbano como instrumento para garantir seus 
privilégios e benefícios e não algo para democratizar a política urbana, o que faculta o direito à cidade para a maior parte da população.

Ferreira, Moraes e Pereira (2012) apontam que o Estatuto da Cidade e o Plano Diretor, principais leis que auxiliam e orientam o planejamento e a gestão urbana, ao trazer a síntese para as suas diversas políticas públicas, têm boas intenções por traçar diretrizes para a construção de uma cidade sustentável. Todavia, o que acontece na prática é que os interesses da elite local não permitem a viabilização das políticas propostas por eles. Os interesses individuais dessa classe sempre são mais importantes e põem em detrimento os interesses coletivos.

As políticas e propostas, materializadas em formas regulamentadas (ou não) do planejamento urbano, têm servido então para aumentar a exclusão territorial das cidades, ao invés de incluir. Como forma de modificar essa realidade, Ronik (2003) aponta três estratégias para desconstruir tal fato, com base na política urbana: distribuição de investimentos, regulação urbanística e gestão urbana. Para a autora, o mais importante é a democratização da gestão urbana e dos processos decisórios. A participação no planejamento urbano é um instrumento essencial para que os setores populares possam contribuir efetivamente na construção de um outro projeto de cidade.

\section{LUTAR PARA PLANEJAR, PLANEJAR PARA LUTAR}

Por entender que o planejamento, como foi construído ao longo da história e nos dias atuais, não serve para atender as reais necessidades da população, é fundamental sopesar um projeto de cidade para obter transformações sociais. Certos autores propõem a ideia de um planejamento urbano crítico, que não deve ser autoritário ou advir de um único local social. Ele deve ter participação da população, dos mais variados sujeitos da sociedade nos processos de decisão, e deve ser radicalmente democrático, assim como manter-se vigilante ao senso comum, sempre questionando o inquestionável (SOUZA, 2001).

Um planejamento urbano que de fato tenha interesse em transformar a realidade da cidade, que é marcada pela desigualdade, não pode esconder os diversos conflitos existentes, como é a prática comum tanto no modelo modernista quanto no estratégico. Ao contrário, deve partir deles e, principalmente, dos sujeitos que estão na linha de frente dos conflitos, para através de suas experiências com os problemas cotidianos da cidade e dos conflitos existentes com os interesses dominantes locais vislumbrar uma outra cidade, que seja capaz de superar as desigualdades que historicamente são parte de sua realidade. Autores como Tanaka (2017), Vainer et al (2013), Holston 
(2016) os compreendem como planejamentos alternativos, com base nos conflitos sociais, ou planejamento conflitual, comunitário, radical e insurgente, porque podem ser uma solução possível para a questão urbana no Brasil e no mundo

Para o avanço da mobilidade urbana, pensada de forma integrada, vários autores discutem o papel do Estado: Caccia (2015), por exemplo, aponta que é papel do Estado, com base em suas políticas públicas e regulamentações, conduzir o processo de planejamento, do mesmo modo que fazer os investimentos necessários, com objetivo de integrar a mobilidade urbana com as outras políticas sociais, e dessa forma prover a infraestrutura coerente para o desenvolvimento da mesma.

Libardi (2014) aponta que os deslocamentos a pé e em bicicleta dificilmente são colocados como prioridade, ou nem mesmo aparecem no planejamento urbano. Isso se dá por dois motivos principais: primeiramente, por falta de interesse político, pois esses modais não apresentam valor de mercado; e também por eles atenderem principalmente aos pequenos trajetos, os quais são desconsiderados e raramente aparecem nas estratégias do planejamento.

Especificamente sobre as políticas de mobilidade no Brasil, elas são propostas para manter a estrutura da cidade voltada para o transporte particular e motorizado, e priorizam cada vez mais a circulação de automóveis, em detrimento do melhoramento do transporte público e coletivo e das condições das vias para o deslocamento não motorizado.

O agravamento das contradições urbanas, principalmente os problemas relacionados à má qualidade da mobilidade, que dificultam o exercício do direito à cidade, tem gerado grande insatisfação, a qual tem resultado direto nos diversos movimentos que ocuparam as ruas das grandes e médias cidades brasileiras, nas últimas décadas. Nesse sentido, com base na contribuição de Harvey (2008), Fix, Ribeiro e Prado (2015) e Houston (2016), é fundamental para a análise da mobilidade urbana ter em vista as experiências de lutas em curso na sociedade civil, especialmente os movimentos que colocam em questão o próprio Estado e a lógica de mercado, e por meio desse, por esses e para esses sujeitos fazer o ato de planejar.

Assim, fica a reflexão exposta por Vainer et al (2013), de que o mais importante no planejamento não é esconder e mediar os conflitos, mas o reconhecimento dos mesmos, e por meio desses extrapolar a capacidade imaginativa dos sujeitos, suas possibilidades de ações e concepções contra-hegemônicas. A busca pelo planejamento conflitual é uma possível saída para a crise urbana e, segundo o autor, seria a "aposta na capacidade dos processos conflituosos de construírem sujeitos coletivos aptos a ocuparem, de forma autônoma, a cena pública" (VAINER et al, 2013, P. 17). É nesse 
tipo de planejamento e nessa visão de construção da cidade que este artigo se orienta e que suas proposições acerca do desenvolvimento do uso da bicicleta se alicerçam.

\section{USO DA BICICLETA: UMA NOVA MANEIRA DE PENSAR E CONSTRUIR A CIDADE}

Cáccia (2015), Silveira (2010) e Fix, Ribeiro e Prado (2015) constatam que no mundo contemporâneo a grande utilização de automóveis individuais trouxe uma série de problemas para a vida coletiva, como, por exemplo, os crescentes congestionamentos. E isso é algo histórico na formação das cidades no mundo, onde a infraestrutura foi construída, após a Revolução Industrial, para conformar uma rede de transporte que tem como principal objetivo suprir as necessidades dos veículos automotores. Espaços que seriam de uso dos pedestres, como passeio e espaços públicos, foram reduzidos, em detrimento do alargamento das vias, e os espaços para ciclistas e skatistas, como as ciclovias, quase nunca foram colocados como prioridade para o poder público.

A produção de um sistema de transporte que dê prioridade aos modais e padrões das elites, como o feito na maioria das cidades brasileiras, onde os modos motorizados se sobrepõem aos coletivos e não-motorizados, tem como finalidade aumentar o abismo entre as classes sociais, pois assim melhora a acessibilidade e mobilidade de um pequeno grupo, em detrimento da maioria da população (VILLAÇA, 1998).

Essa prioridade, que é marca hegemônica da atual política de mobilidade nas cidades brasileiras, segundo Boareto (2008), não é resultado da "falta de planejamento" ou de conscientização das vantagens dos transportes não-motorizados e coletivos. Isso reflete uma visão de cidade, que se configura em defesa dos interesses das elites econômicas, cujo automóvel é um dos seus maiores símbolos. Ainda conforme o autor, as cidades em que a mobilidade é baseada apenas no desenvolvimento do uso do automóvel "constituem uma linha de vanguarda do atraso". (BOARETO, 2008, p. 146)

O transporte individual e motorizado é "vendido" pelo poder público e pela indústria automotiva como a solução para os problemas de mobilidade nos grandes e médios aglomerados humanos e, assim, há o aumento significativo dos números de carros e motos nas ruas, o que traz diversos problemas para a vida coletiva nas cidades, como o aumento nos engarrafamentos e do número de acidentes.

Um ponto fundamental na problemática da mobilidade urbana, sob a chave do direito à cidade para a maioria da população, é a crítica ao automóvel como a solução para os problemas diários dos deslocamentos. Contudo, além da dimensão teórica, esse é um processo de mudança que envolve o 
desenvolvimento dos moldais coletivos e não motorizados. E a principal forma não motorizada utilizada no mundo contemporâneo e que apresenta maiores benefícios à coletividade, como o baixo custo de fabricação, compra e manutenção, eficiência energética, desenvolvimento da saúde, rapidez e pouca ocupação de espaço, é a bicicleta (CONCEIÇÃO, 2016).

Todos esses elementos apresentados, principalmente o seu baixo custo, demonstram que a bicicleta é um meio de transporte acessível para a maior parte da população e o seu engendramento pode promover maior igualdade no uso do espaço público e ajudar a desenvolver o direito à cidade. A bicicleta tem grande valor para os deslocamentos de pequenas e médias distâncias, e com a necessária integração com os outros modais de transporte coletivo pode se tornar um veículo essencial para o deslocamento por toda cidade (XAVIER, 2009).

A bicicleta é o veículo mais utilizado nas cidades brasileiras com menos de 50 mil habitantes, que correspondem a $92,2 \%$ do total (IBGE, 2010). Nessas, em geral, o transporte coletivo raramente existe e os veículos motorizados não estão ao alcance de grande parte da população. Já nas cidades médias e grandes, os números são diferentes. Há muito menos utilização da bicicleta do que o seu potencial, que geralmente fica restrita a dois setores da população: os que têm as rendas mais baixas e a classe média-alta. Segundo Conceição (2016), os de classe média alta utilizam a bicicleta, na maioria das vezes, com esporte ou lazer; e os de renda baixa a utilizam como principal meio para se deslocar para quase todas as suas atividades, já que o transporte coletivo, em geral, é precário e caro, sendo o setor que mais utiliza a bicicleta no país, segundo o Ministério das Cidades (BRASIL, 2007; 2012).

A bicicleta é o veículo individual mais utilizado no Brasil e o único capaz de alcançar quase todos os indivíduos da sociedade, independente de renda, idade ou motivo de uso. Segundo Coelho Filho e Saccaro Junior (2017), o país tem cerca de 50 milhões de bicicletas, contra 41 milhões de carros, por exemplo, e $7 \%$ das viagens totais são feitas por bicicletas, com o potencial de $40 \%$.

Outro fato é que, numa sociedade em que o tempo dos indivíduos está cada vez mais escasso, que o ritmo de trabalho e estudo, por muitas vezes, ocupa todo o seu tempo, poder fazer uma atividade física no deslocamento para o trabalho ou estudo, por exemplo, ajuda a pessoa a manter sua forma física. Isso, sem precisar desprender de mais tempo para outra atividade corporal, e assim fugir do sedentarismo e dos problemas a ele relacionados, porque aumenta e mantém a aptidão física e desenvolve a saúde. Ao saber que grande parte dos ciclistas é advinda da população com menor renda e que a saúde como direito do cidadão é de difícil acesso e/ou não tem qualidade, o uso da bicicleta se configura também como direito à saúde. Para Westphal e Olievira (2015), esse direito não é ter 
apenas ingresso a um sistema de saúde, isto é só uma parte do processo, como, também, ter moradia digna, trabalho, lazer, educação, mobilidade urbana de qualidade, entre outros requisitos.

Em comparação aos modais motorizados, o uso da bicicleta ainda favorece ao meio ambiente, pois é um modal livre de produção de gases poluentes, já que toda energia utilizada para o seu movimento é realizada pelo próprio corpo humano. Silva (2017) comenta que o uso da bicicleta proporciona uma cidade mais agradável ambientalmente e, por consequência, menos nociva à saúde.

Segundo o Ministério das Cidades, "[...] a inclusão da bicicleta nos deslocamentos urbanos pode ser considerada elemento fundamental para a implantação do conceito de mobilidade urbana para a construção de cidades sustentáveis" (BRASIL, 2007, p.8). Isso, pois a bicicleta reduz o custo da mobilidade dos indivíduos e possibilita que as pessoas se desloquem pela cidade com menor dispêndio de recursos e, assim, democratiza a mobilidade urbana e dá acesso, consequentemente, ao direito à cidade.

O desenvolvimento do uso da bicicleta pode levar à construção de cidades sustentáveis e saudáveis, visto todas as vantagens a ela atribuídas. Porém, só com a transformação radical da sociedade, que vai além da mobilidade urbana, ou seja, uma mudança estrutural do sistema econômico, político, cultural, é que de fato pode-se construir cidades realmente saudáveis e, sobretudo, sustentáveis. Enquanto as premissas do capitalismo reinar, fora medidas paliativas, esses objetivos ainda estarão distantes de serem alcançados.

Ao prosseguir com as vantagens do uso da bicicleta, Fabiano (2016) comenta que ela aparece como uma alternativa perante a situação do transito caótico, além inserir setores que são excluídos do sistema convencional de transporte, por não ter renda suficiente, o que democratiza a apropriação do espaço público.

O uso da bicicleta como um modo de mobilidade urbana é, por um lado, uma afronta aos grandes interesses de quem mais lucra com o caos da mobilidade nas médias e grandes cidades. Com o desenvolvimento do seu uso, mais pessoas poderão utilizar a bicicleta e haverá menos necessidade da utilização dos carros no cotidiano, o que vai de frente aos interesses da indústria automobilística, que, a partir do século XIX, ditou as regras do funcionamento das cidades, pois as vias são construídas para o automóvel se deslocar e não para os modos não-motorizados. Também confronta os interesses dos empresários do transporte, pois, com o desenvolvimento da infraestrutura para o uso da bicicleta, mais pessoas poderão optar em não utilizar o transporte coletivo caro ou de qualidade precária, para usar a bicicleta, o que fará os empresários se reinventarem; forçará melhorias na qualidade do seu serviço e até poderá reduzir tarifas. 
Andar de bicicleta se configura, para além de uma prática de locomoção, seja por motivos de trabalho/estudo ou de esporte/lazer, como um engajamento político, social e ambiental, justamente por ir na contramão do que é estabelecido como regra nas vias brasileiras, cujo carro é o elemento protagonista. Ou seja, adotar a bicicleta como principal modal de mobilidade no Brasil é um ato de resistência, portanto, ser ciclista no Brasil é, de certo modo, ser resistência ao sistema. Além disso, por essa prática garantir, segundo Lins et al (2016), melhoria na qualidade de vida, minimizar gases poluentes, diminuir engarrafamentos e acidentes e, por consequência, mortes no trânsito, concede ao cidadão maior possibilidade de adquirir e efetivar o direito à cidade.

Ao falar em direito à cidade, César (2010) explana que a inserção da bicicleta é uma forma de democratizar as diversas possibilidades que a cidade produz e tem a oferecer. Com a sua priorização, conjuntamente com os modais coletivos, a cidade será "[...] mais democrática e o direito à cidade estará mais próximo" (CÉSAR, 2010, P.8).

O uso e desenvolvimento da bicicleta é uma maneira de garantir esse direito tão fundamental para a vida dos sujeitos, sobretudo o trabalhador. $O$ direito de usufruir todas as qualidades que a vida urbana pode oferecer e colocar sua prática cotidiana como uma experiência aceitável para o conjunto da sociedade. Através do poder de se locomover que a bicicleta democratiza, permitir desfrutar do espaço urbano com mais qualidade, liberdade e autonomia e, portanto, tomá-lo como seu de direito, fato que a classe dominante, em conjunto com o Estado, sempre dificultou e buscou negar.

\section{USO DA BICICLETA NAS CIDADES BRASILEIRAS: PROBLEMAS E CAMINHOS DO PLANEJAMENTO}

Para a circulação da bicicleta nas cidades brasileira é fundamental uma série de intervenções que facilitem seu uso, principalmente a construção de infraestrutura necessária para isso, como ciclovias, ciclofaixas, ciclorrotas, bicicletários, paraciclos, sinalização, etc. Cada uma dessas infraestruturas citadas compre um papel na dinâmica do ciclista e pode ser implementada em função da viabilidade técnica, do espaço disponível nas vias e também através da sua necessidade social.

Tais infraestruturas são classificadas em três: espaços compartilhados, espaços parcialmente segregados e espaços totalmente segregados. Segundo Gondim (2010), os espaços compartilhados são aqueles em que há possibilidade do trânsito entre mais de um modal, por exemplo, a bicicleta e o carro ou a bicicleta e o pedestre. Ciclorrotas são exemplos desse tipo de espaço, pois são rotas compartilhadas com sinalizações horizontais ou verticais, que têm como função tanto orientar o ciclista, quanto informar aos condutores dos modais motorizados que aquela via é partilhada. 
Os espaços parcialmente segregados são aqueles em que há utilização mista, que são destinados ao uso de bicicleta, porém, também podem ser utilizados por veículos motorizados. Podem estar tanto nas margens da pista quanto no meio, entre uma via de automóveis e outra, sendo que não há nenhum obstáculo físico para separa-los das outras vias. Um exemplo é a ciclofaixa, que são "as faixas nas pistas de rolamento, ou nas calçadas, delimitadas pela sinalização horizontal ou diferenciação do piso, sem utilização de obstáculos físicos" (GONDIM, 2010, p. 54).

Os espaços totalmente segregados, para Gondim (2010), são os destinados ao uso exclusivo dos ciclistas e há um obstáculo físico para separar das outras vias, como os meios-fios, muretas e calçadas; podem estar também no centro de um canteiro. Um exemplo é a ciclovia, que, segundo o autor, tem essa definição: uma via segregada, de uso específico de bicicletas, separada por uma barreira física.

Outra infraestrutura importante para o melhor desenvolvimento do uso da bicicleta, já que garante maior segurança contra furtos do equipamento, são os estacionamentos específicos. Segundo o Instituto de Políticas de Transporte e Desenvolvimento (ITDP, 2009), há duas formas de estacionamento: paraciclos e bicicletários. O primeiro garante a segurança mínima e são geralmente estruturas férreas, fixadas no piso, na parede ou no teto, nas quais a bicicleta pode ser trancada com uma corrente ou cadeado. Já os bicicletários, que também utilizam essa forma de proteger o equipamento, são mais seguros, pois oferecem acesso controlado ao espaço, geralmente fechados, e podem inclusive oferecer outros serviços aos ciclistas.

Porém, em geral, nas cidades brasileiras há descaso do poder público em relação ao desenvolvimento dos modos não motorizados, o que acarreta na falta de políticas e das infraestruturas adequadas, citadas acima, e dificulta o desenvolvimento efetivo desse modal. O número de ciclistas cresce a cada dia, porém as facilidades voltadas a eles são implementadas de maneira lenta, isso quando são implementadas, principalmente devido aos problemas no planejamento intermodal dos sistemas de transportes (VASCONCELOS, 2000). Dessa forma, "Conclui-se que a adoção de políticas coerentes e a implantação de infraestruturas para o ciclismo são condições essenciais para maior utilização da bicicleta como meio de transporte (SILVEIRA, 2010, p. 5) ".

Apesar de ser um modal que apresenta boa viabilidade, a bicicleta ainda é menos utilizada do que seu potencial, sobretudo, em cidades médias e grandes do país. E esse é um problema explicado pela falta de políticas necessárias pelo poder público e, em consequência, também pela falta de infraestrutura adequada para tais atividades. 
Castañon (2011, p. 4), ao abordar o uso da bicicleta como mobilidade sustentável, expõe que "diversos fatores explicam a resistência ao uso da bicicleta como meio de transporte: insegurança quanto a atropelamentos, possibilidade de assaltos, falta de estacionamentos e ausência de ciclovias". Então, mesmo com todos os aspectos positivos, grande parte da população continua a utilizar os modais tradicionais, pois há um sentimento de insegurança com os trajetos, que pode custar a vida dos ciclistas, ou no mínimo, a perda de seu material. Para se ter uma ideia, entre 2010 e 2020, segundo a Associação Brasileira de Medicina de Tráfego (ABRAMET, 2020), ocorreram 13.718 mortes de ciclistas, das quais $60 \%$ por atropelamentos, o que gerou um gasto anual de até $\mathrm{R} \$ 15$ milhões para o Sistema Único de Saúde (SUS). Portanto, só com uma política bem estruturada de mobilidade urbana, que de fato priorize as formas não motorizadas, com a construção de infraestrutura adequada para sua utilização, é que a população sentirá mais segura para adotar a bicicleta como sua forma principal de deslocamento.

Miranda, Citadin e Alves (2009) falam da reinserção da bicicleta no trânsito das cidades e que são necessários dois caminhos para isso: primeiro, que haja a disseminação de locais para a parada, ou seja, estacionamentos, que podem ser paraciclos ou bicicletários; e, em segundo lugar, a retirada de espaços ocupados pelos meios motorizados, como, por exemplo, as áreas de estacionamentos de automóveis que se estendem ao longo das vias.

Para haver uma transformação radical das cidades brasileiras, no que diz respeito a construção de suas vias e a mobilidade urbana como um todo, transformando-as em cidades acessíveis a quem utiliza a bicicleta, é necessário, segundo Raquel (2010), que haja um planejamento cicloviário, conjuntamente com outros processos de planejamento, com base na participação popular, em que a população que anda de bicicleta possa participar e construir formas de transformar o espaço clicloviário, conjuntamente com pareceres técnicos. Ou seja, construir uma nova mobilidade da cidade por meio das pessoas que enfrentam os problemas e os conflitos de se deslocar de forma alternativa no espaço urbano. Caso contrário, a tendência é a continuação de cidades que não têm infraestrutura básica para o uso seguro e confortável da bicicleta e/ou construções de espaços cicloviários tão quantos perigosos e pouco atraentes para ciclistas. Ainda segundo a autora, a implantação de um sistema cicloviário de qualidade irá estabelecer maior segurança para os usuários, além de atrair novas pessoas interessadas em adotar a bicicleta como o seu principal modo de mobilidade.

O Ministério das Cidades ainda aponta que o planejamento cicloviário deve partir da premissa que existem duas estratégias básicas que devem andar juntas e se combinar ao longo de todo o processo do plano: uma técnica e outra de discussão social. A realização constante de pesquisas 
sobre a mobilidade dos usuários de bicicleta, suas constatações sobre os problemas enfrentados na locomoção diária, perspectivas, propostas, seus hábitos e demandas específicas, constitui um elemento essencial no processo de planejamento. É importante também que os espaços de discussão que venham a acontecer sejam com base em informações sistematizadas sobre uma série de questões relevantes em relação ao uso da bicicleta, como infraestrutura e a demanda de oferta de serviços, adquiridas pela aplicação de metodologias técnicas (BRASIL, 2007).

Segundo o Ministério dos Transportes, outra característica importante para o planejamento cicloviário é a classificação e o mapeamento das áreas e estabelecimentos que têm potencial de ocasionar viagens de bicicleta, como, por exemplo, escolas, universidades, indústrias, centros comerciais, espaços da construção civil, além dos terminais dos modais coletivos, as praças de esporte, entre outros locais, que variam a depender da dinâmica de cada cidade. Por meio disso e da consulta aos sujeitos que lidam diretamente com o ciclismo, fica mais fácil a escolha de áreas que possam sofrer intervenções urbanísticas para o melhoramento do uso da bicicleta (BRASIL, 2012).

Outro ponto importante e que pode acarretar em um maior estímulo para o uso da bicicleta é a integração da mesma com outros modais de transporte coletivo, como ônibus, trens, metros, barcos, etc. Isto tem a função de conciliar as viagens de pequenas distâncias, ideais para o uso de bicicleta, e as de médias e grandes distâncias, que não são muito recomendadas para o uso nãomotorizado no cotidiano, principalmente nas grandes cidades. Com essa integração, o ciclista pode fazer um percurso curto de bicicleta e depois ter acesso a outro modo coletivo para continuar a viagem.

A integração pode ser realizada de duas formas, segundo o Ministério das Cidades: por meio de provimento de estacionamento com tarifa integrada, ou seja, nos terminais de transporte coletivo devem existir bicicletários que garantam que o ciclista possa guardar o seu equipamento com segurança e, após voltar de sua viagem, reatá-lo. A outra é através do embarque da bicicleta no modal coletivo, onde os ciclistas podem embarcar no metrô com as suas bicicletas, por exemplo, ou quando seguem viagem com o seu equipamento no ônibus, tanto na parte interior do veículo, quanto no seu exterior. Dessa forma, o ciclista percorreria o trajeto curto até o terminal, embarcaria seu equipamento no modal coletivo rumo a uma localidade mais distante e depois prosseguiria a viagem por outro percurso curto com a sua bicicleta (BRASIL, 2007).

A integração cumpre dois objetivos diretos: “1) - incluir a bicicleta como modo de transporte habitual nas viagens por motivo de trabalho nas cidades; 2 ) reforçar modos coletivos como principais meios de transporte para viagens médias e longas das populações nos médios e grandes aglomerados humanos" (BRASIL, 2007, p. 176). 
A integração através desses elementos discutidos estimula a bicicleta a ser um modo coadjuvante das viagens principais realizadas por outros modais, realidade das médias e grandes cidades, pois nas pequenas ela se caracteriza como protagonista, e tem função de contribuir com a formação e crescimento de cidades sustentáveis, de acordo com Souza, Lima Neto e Brasileiro (2009). Além disso, a integração precisa se adequar as práticas diárias e coletivas já existentes das pessoas das cidades.

O planejamento então é essencial para que a cidade se torne mais agradável, mais viável, segura e difunda o uso da bicicleta pela população, pois não são ações isoladas, como a construção de uma ciclovia ou ciclofaixa desconectada com uma rede clicloviária mais ampla, que irão resolver os problemas relacionados ao seu uso. O planejamento cicloviário inadequado, o que é regra nas ruas, e o ciclista a disputar espaço com os automóveis, em vias estreitas e sem espaço suficiente para o uso da bicicleta, já que os espaços específicos raramente existem, tornam os deslocamentos diários pelas cidades sempre um risco a vida dos usuários.

Além disso, paraciclos e bicicletários também são exceções. A regra é ciclista estacionar seu equipamento em árvores, postes e outras estruturas férreas, que não garantem segurança (CONCEIÇÃO, 2016). Ou seja, sem esse planejamento as condições da cidade em geral tornam-se desfavoráveis para o uso da bicicleta, o que acarreta em menos uso desse modal.

César (2010) comenta que apenas a construção de ciclovias isoladas não é suficiente para contemplar quem utiliza a bicicleta. Uma série de questões precisam ser debatidas e construídas, como o conjunto de infraestruturas já discutidas e a integração com outros modais coletivos. Além disso, o poder público precisa realizar campanhas de respeito e conscientização dos condutores de automóveis e fiscalização do trânsito. A bicicleta tem que andar nas ruas, junto com os carros, e para isso, medidas de custos baixos e rápidas, em comparação às voltadas aos veículos motorizados, têm mais efetividade e possibilitam o tráfego com mais segurança e conforto nas ruas, sem a necessidade de redesenhá-las. "A partir do momento que tais medidas forem tomadas, a bicicleta terá uma visibilidade maior, o número de ciclistas e a segurança vão aumentar. As ruas se tornarão mais vivas, menos impessoais, e o direito à cidade estará mais próximo" (CÉSAR, 2010, p.13).

Por meio de todas essas questões levantadas sobre o planejamento do uso da bicicleta, fica a reflexão que o mesmo só é possível com a participação ativa dos indivíduos que, na sua prática cotidiana, a utilizam como forma de se deslocar pela cidade, e sentem no dia a dia as vantagens de adotar essa forma de se locomover e viver e as desvantagens e todos os problemas e conflitos que dificultam o melhor uso desse modal. O planejamento cicloviário deve ser feito por meio das premissas 
do planejamento conflitual, porque coloca esse sujeito que está no centro desse problema como protagonista do processo.

\section{CONSIDERAÇÕES FINAIS}

Algo notado no texto é que a mobilidade torna-se essencial para a melhoria da qualidade de vida urbana, porque é parte integrante e importante da cidade contemporânea. Sem uma mobilidade eficiente e democrática, a cidade não tem como funcionar e existir, pois para a população acessar a qualquer atividade ou serviço disposto no espaço é necessário se deslocar, se movimentar, sair de suas casas e ir desfrutar dos benefícios do meio urbano. Então, se o direito à mobilidade urbana não é garantido, outros direitos fundamentais também estarão comprometidos, como o direito à saúde, à educação, ao trabalho, ao lazer; na verdade, o direito de existir na cidade.

Os modos não motorizados são os essenciais para a mobilidade urbana no Brasil, sobretudo a bicicleta, por diversas questões apontadas: primeiro, junto com caminhadas, a bicicleta é o modo mais viável e acessível financeiramente para a maior parte da população, devido ao seu baixo custo de investimento e manutenção, sendo um dos modais mais democráticos e que mais permitem o amplo acesso aos espaços urbanos e a todos os seus benefícios (educação, trabalho, lazer, esportes, etc.), por garantir que a população, sobretudo, a de menor renda, tenha acesso ao direito à cidade; em segundo lugar, é um modal que garante melhor qualidade de vida ao indivíduo e à coletividade, pois ajuda na saúde, por exercer uma atividade física e não poluir a atmosfera; e, em terceiro, adotar a bicicleta ou outros modais não motorizados ajuda a controlar o alto número de automóveis, que, nas últimas décadas, cresceu nas cidades brasileiras e acentuou os congestionamentos cotidianos, além de acidentes.

Porém, este artigo não defende que apenas a bicicleta solucionará todos os problemas das cidades. A bicicleta precisa ser inserida e integrada à totalidade do sistema de mobilidade urbana, e assim, com a maior importância desse modal, conjuntamente com a maior qualidade do sistema de transporte público como todo, a cidade poderá ser mais saudável, sustentável e, sobretudo, democrática.

Outro ponto a destacar é a importância do planejamento para o desenvolvimento dos municípios, sobretudo, neste caso, o planejamento cicloviário. Porém, historicamente, o planejamento esteve mais preocupado em garantir os benefícios para os setores dominantes e hegemônicos da 
cidade, do que a resolver os seus reais problemas e contribuir para o acesso ao direito à cidade a maior parte da população.

Todavia, mesmo que sejam feitas essas críticas ao planejamento e apontados seus interesses históricos com a continuação da dominação dos setores hegemônicos, é necessário que a sociedade civil dispute esse espaço e lute para que haja um planejamento que fuja dessa lógica. A construção de um planejamento crítico, com base nos problemas e conflitos das realidades da cidade e, principalmente, que seja mais democrático, construído conjuntamente com os sujeitos que vivem de fato os problemas em seu cotidiano.

\section{REFERÊNCIAS}

ABRAMET. Medicina do tráfico, São Paulo: ABRAMET, 2020. Disponível em: https://abramet.com.br. Acesso: 05 mai. 2020

BOARETO, Renato. A política de mobilidade urbana e a construção de cidades sustentáveis. Revista dos Transportes Públicos, ANTP, Santa Maria - RS, Ano 30/31, 2008. p. 143-160

BRASIL. Ministério das Cidades. Caderno de referência para elaboração de plano de mobilidade por bicicleta nas cidades. Brasília: Ministério das Cidades, 2007.

BRASIL. Lei 12.587, de 03 de janeiro de 2012. Institui as diretrizes da Política Nacional de Mobilidade Urbana. Disponível em: http://www.planalto.gov.br/ccivil_03/_ato2011- 2014/2012/lei/l12587.htm . Acesso: 15 maio. 2016.

CACCIA, Lara Schimitt. Mobilidade urbana: políticas públicas e apropriação do espaço em cidades brasileiras, 2015. 184f. Dissertação (Mestrado em Geografia)-Universidade Federal do Rio Grande do Sul, Porto Alegre, 2015.

CASTAÑON, Ugo Nogueira. Uma proposta de mobilidade sustentável: o uso da bicicleta na cidade de juiz de fora. 2011. 105f. Dissertação (Mestrado em Engenharia de Transportes)-Universidade Federal do Rio de Janeiro (UERJ), Rio de Janeiro, 2011.

CÉSAR, Yuriê Baptista. A garantia do direito à cidade através do incentivo ao uso da bicicleta nos deslocamentos urbanos. In: Mobilze, 2010. Disponível em:

http://www.mobilize.org.br/midias/pesquisas/a-garantia-do-direito-a-cidade.pdf. Acesso: 19 jun. 2018.

COELHO FILHO, O.; SACCARO JUNIOR, N. L. Cidades cicláveis e desafios das políticas cicloviárias no Brasil. Repositório de Conhecimento do IPEA, 2017. Disponível em:

http://repositorio.ipea.gov.br/handle/11058/7521. Acesso: 21 jul. 2018.

CONCEIÇÃO, Bruno da Silva. Avaliação técnica de ciclovias em Feira de Santana: estudo de caso da ciclovia da Avenida Presidente Dutra. 2016. 176f. Trabalho de Conclusão de Curso (Graduação em Engenharia Civil)-Universidade Estadual de Feira de Santana, Feira de Santana, 2016. 
COUTINHO, Carlos Nelson. De Rousseau a Gramsci: Ensaios de Teoria Política. São Paulo, Boitempo Editorial, 2011.

ENGELS, Friedrich. A origem da família, da propriedade privada e do Estado. 3 a Ed., são Paulo: Editora expressão Popular, 2012.

FACCIO, Maria da Graça Agostino. Plano diretor participativo nas cidades brasileiras a partir do estatuto das cidades: possibilidades e limites. Cadernos de Pesquisa Interdisciplinar em Ciências Humanas, v. 7, n. 82, 2006, p. 1-10

FERREIRA, W. R; MORAES, S. D. Q.; PEREIRA, L. A G. A geografia dos transportes na organização do espaço urbano: mobilidade e acidentes de trânsito. In: Revista Caminhos da Geografia, v. 13, n. 42, 2012, p. 240-257

FIX, Mariana; RIBEIRO, Giovani Espíndola; PRADO, André Doca. Mobilidade urbana e direito à cidade: uma entrevista com Lúcio Gregori sobre transporte coletivo e Tarifa Zero. Revista Brasileira de Estudos Urbanos, v. 17, n.13, 2015, 175-191.

GONDIM, M. F. Caderno de desenhos: ciclovia. Rio de Janeiro: Editora da COPPE/UFRJ, 2010.

FABIANO, Maria Lucia Alves. A mobilidade urbana e o papel da bicicleta como indutor de inclusão social e de transformação da cidade. In COLÓQUIO BRASIL-PORTUGAL, 4, Portal Mackenzie, Anais..., 2016.

GRAMSCl, Antonio. Maquiavel, a política e o estado moderno. 5a Ed., Rio de Janeiro: Editora Civilização Brasileira, 1984.

ENGELS, F; MARX, K. A Ideologia alemã. São Paulo: Boitempo Editorial, 2007.

HARVEY, David. O direito à cidade. New Left Review, n. 53, 2008, p. 73-89. Disponível em: http://www4.pucsp.br/neils/downloads/neils-revista-29-port/david-harvey.pdf. Acesso: 15 jul. 2016. A produção capitalista do espaço. São Paulo: Editora Annablume, 2005.

HOLSTON, J. Rebeliões metropolitanas e planejamento insurgente no século XXI. Revista Brasileira de Estudos Urbanos e Regionais, v.18, n.2, mai-ago, 2016. p.191-204

IBGE. Censo Demográfico, Rio de Janeiro: IBGE, 2010. Disponível em: http://www.ibge.gov.br/censo2010/. Acesso: 05 mai. 2018

ITDP. Manual de bicicletários modelo ASCOBIKE. Mauá. ASCOBIKE, 2009.

LENIN, Vladimir Llitch. O Estado e a revolução: o que ensina o marxismo sobre o Estado e o papel do proletariado na revolução. 2a Ed., São Paulo: Editora Expressão Popular, 2012.

LIBARDI, Rafaela. Mobilidade urbana frente à complexidade urbana. Revista EURE, Santiago, vol. 40, no 121, 2014, p. 273-276 
LINS, Dannilo de Loiola Pessoa Bezerra; PESSOA, Daniel Leito; GOMES, Adriano Lopes. Vem de bike: transportes e mobilidade. In: EXPOSIÇÃO DA PESQUISA EXPERIMENTAL EM COMUNICAÇÃO, Anais... Natal/ RN: Intercom, 2016

MARICATO, E. As ideias fora do lugar e o lugar fora das ideias: planejamento urbano no Brasil. In: ARANTES, O. B.F; VAINER, C.; MARICATO, E (Org.). A cidade do pensamento único: desmanchando consensos. 3. ed. petrópolis, 2002. p. 121-192.

MARICATO, Ermínia. Brasil, cidades: alternativas para a crise urbana. 4 Ed. Petrópolis, Rio de Janeiro: Vozes, 2011.

MARICATO, Ermínia. Globalização e política urbana na periferia do capitalismo. Revista VeraCidade, Salvador, BA, ano IV, no 4, 2009, p. 1-25

MOCHI, C. M. A constituição do estado moderno: do ideal de liberdade para o princípio da dignidade humana. In: Revista do Direito Público, Londrina, v. 4, n. 1, 2009. p. 1-26

MIRANDA, A. C. M.; CITADIM, L. L. B.; ALVES, E. V. A importância das ciclofaixas na reinserção da bicicleta no trânsito urbano das grandes cidades. In: CONGRESSO BRASILEIRO DE TRANSPORTE E TRÂNSITO, 17, 28 de setembro a 2 de outubro de 2009, Anais..., Curitiba: ANTP, 2009.

POULANTZAS, N. O Estado, o poder, o socialismo. Rio de janeiro, Edições Graal, 1980.

RAQUEL, Roberta. Espaço em transição: a mobilidade ciclística e os planos diretores de Florianópolis. 2010. 163 f. Dissertação (Mestrado em Geografia)-Pós-Graduação em Geografia, UFSC, FlorianópolisSC, 2010.

SOUZA, Carlos Augusto Elias de; NETO, Oslwaldo Lima; BRASILEIRO, Anísio; Integração modal entre bicicletas com o transporte público de massa para o desenvolvimento sustentável de cidades.

CONGRESSO DE PESQUISA E ENSINO EM TRANSPORTES, 23, 2009, Anais.... Vitória/ES: ANPET, 2009.

RONIK, Raquel. Política urbana no brasil: esperança em meio ao caos? In: Revista dos Transportes Públicos, ANTT, ano 25, 2003, p. 11-18.

SANTOS, Boaventura de Souza. O estado e os modos de produção de poder social. In: Oficina do CES, no 7, p. 1-27, 1989. Disponível em https://estudogeral.sib.uc.pt/bitstream/10316/10916/1/O\%20Estado\%20e\%20os\%20Modos\%20de\% 20Produ\%C3\%A7\%C3\%A30\%20de\%20Poder\%20Social.pdf. Acesso: 08 jul. 2018.

SILVA, José Borzacchiello da. O "Estatuto da Cidade" e a reforma urbana no Brasil". São Paulo: Geousp, Espaço e Tempo, São Paulo - SP, no 10, 2001, p. 10-26

Planejamento urbano e crises das cidades. Terra Livre, Presidente Prudente/SP, ano 24, V. 1,2008, p. $83-96$

SILVA, Maria Euzimar Berenice Rego Silva. O Estado em Marx e a teoria ampliada do Estado em Gramsci. Campinas, SP. In: COLÓQUIO INTERNACIONAL MARX ENGELS, 4. Anais..., Cemarx, 1999. Disponível em: 
http://www.unicamp.br/cemarx/ANAIS\%20IV\%20COLOQUIO/comunica\%E7\%F5es/GT2/gt2m5c5.pdf >. Acesso: 07 jul. 2018.

SILVA, Mario Sergio Silva da. O uso de bicicletas como modal para a mobilidade urbana no município de Castanhal, estado do Pará. Gestão de Trânsito, Unisul Virtual, Castanhal, PA, 2017. Disponível em: https://riuni.unisul.br/handle/12345/2386. Acesso: 23 jul. 2018

SILVEIRA, Mariana Oliveira. Mobilidade sustentável: a bicicleta como um meio de transporte integrado. 2010. 155 f, Dissertação (Mestrado em Engenharia de Transportes)-COPPE-Universidade do Rio de Janeiro, Rio de Janeiro, 2010.

SOUZA, Marcelo Lopes. Mudar a cidade: uma introdução crítica ao planejamento e à gestão urbanos. Rio de Janeiro: Bertrand Brasil, 2001.

TANAKA, Giselle. Planejamento e conflitos sociais: reflexões a partir lutas urbanas. In: ENCONTRO NACIONAL DA ASSOCIAÇÃO NACIONAL DE PÓS GRADUAÇÃO EM PLANEJAMENTO URBANO (ENANPUR), 17, Anais... Recife, 2017, p. 1 - 19.

VAINER, Carlos B. Pátria, empresa e mercadoria: notas sobre a estratégia discursiva do planejamento estratégico urbano. In: ARANTES, O. B.F; VAINER, C.; MARICATO, E (Org.). A cidade do pensamento único: desmanchando consensos. 3. ed. petrópolis, 2002. p. 75-103.

VAINER, Carlos B et al. O plano popular da vila autódromo: uma experiência de planejamento conflitual. In: ENCONTRO NACIONAL DA ASSOCIAÇÃO NACIONAL DE PÓS GRADUAÇÃO EM PLANEJAMENTO URBANO (ENANPUR), 15, Anais... Recife: UFPE, 2013

VASCONCELLOS, E. A. Transporte urbano nos países em desenvolvimento: reflexões e propostas. São Paulo: Annablume, 2000

VILLAÇA, Flávio. Espaço intra-urbano no Brasil. São Paulo: Studio Nobel, 1998.

VIOLIN, Tarso Cabral. A sociedade civil e o estado ampliado por antonio gramsci. Revista Eletrônica do CEJUR, Curitiba - PR, v. 1, n. 1, ago./dez. 2006. Disponível em <

http://ojs.up.com.br/index.php/raizesjuridicas/article/viewFile/155/128>. Acesso: 05 jul. 2018.

WESTPHAL, Marcia Faria; OLIVEIRA, Sandra Costa. Cidades saudáveis: uma forma de abordagem ou uma estratégia de ação em saúde humana? In: Revista USP, São Paulo -SP, no 107, 2015, p. 91-102

XAVIER, Giselle N. A. et al. Programa de parcerias pela bicicleta (BPP): contribuindo para a inclusão da bicicleta como componente do transporte (público) nas cidades brasileiras. Florianópolis: UDESC, 2009. 
Sobre os autores:
Janio Laurentino de Jesus Santos
Pós-doutorado em Planejamento Urbano, na Universidade do Porto, em Portugal. Doutor em Geografia, pela
UNESP. Professor-Pleno (UEFS), membro permanente do Programa de Pós-Graduação em Planejamento
Territorial (Mestrado Profissional) - PLANTERR (UEFS) e do Programa de Pós-Graduação em Geografia (PPGeo-
UESB). Universidade Estadual de Feira de Santana (UEFS), Feira de Santana, BA, Brasil.
Lattes: http://lattes.cnpq.br/2282494423261197. ORCID: https://orcid.org/0000-0003-0730-1271.
E-mail: janiosantos@yahoo.com.br
Luiz Eduardo Pereira Ferreira dos Santos
Mestre em Planejamento Territorial, Universidade Estadual de Feira de Santana - UEFS; Professor aa Rede
Estadual de Ensino da Bahia. Universidade Estadual de Feira de Santana (UEFS), Feira de Santana, BA, Brasil.
Lattes: http://lattes.cnpq.br/4367635562880571 ORCID: https://orcid.org/0000-0002-1031-0884.
E-mail: edugeouefs@yahoo.com.br
Os autores contribuíram igualmente para a redação do artigo. 